\title{
A IDENTIDADE E LETRAMENTOS ACADÊMICOS MARCADOS ATRAVÉS DA POESIA
}

\author{
Cláudia Calcagno Martins ${ }^{1}$ \\ Veronice Camargo da Silva ${ }^{2}$ \\ Mirna Suzana Vieira de Martinez ${ }^{3}$
}

\begin{abstract}
Resumo: O presente trabalho é resultado de uma pesquisa de cunho qualitativo realizada com os alunos do Projovem Urbano na cidade de Bagé/RS. Partindo do pressuposto de que pensar em identidade é também pensar em língua, ou seja, é pensar na construção identitária como um processo que vai se modificando (HALL, 2011), realizou-se com o intuito de analisar, a partir do modelo dos letramentos acadêmicos (LEA \& STREET, 2006), o processo de construção da identidade dos alunos do Projovem Urbano. Utilizaram-se como instrumentos de análise, marcas linguísticas encontradas em poesias produzidas pelos alunos tendo como referência a poesia "Ou isto ou aquilo", de Cecília Meirelles. Os dados apontam que existe, por parte desses jovens, o desejo de não perder suas raízes, mas com uma vontade de mudar e se tornarem autônomos. Os dados apontam, ainda, um sujeito com uma concepção pós-moderna em que assume identidades diferentes em diferentes momentos. Pondera-se, ainda, que os letramentos acadêmicos estiveram presentes, uma vez que foram além da definição ou uso de regras específicas. Pelo contrário, representaram os diferentes modos pelos quais esses jovens (GEE,1999) valorizam, pensam, acreditam e escrevem através do gênero textual poesia.
\end{abstract}

Palavras-chave: Identidade. Letramentos. Poesia.

1 Especialista em Psicopedagogia Clinica Institucional. Licenciada em Letras pela Universidade Federal do Pampa. E-mail:claudiagcmartins@gmail.com

2 Doutora em Linguística Aplicada. Docente do curso de Pedagogia e do Programa de PósGraduação/Mestrado Profissional em Educação. Universidade Estadual do Rio Grande do Sul/ UERGS. E-mail: veronice-silva@uergs.edu.br

3 Doutora em Educação. Docente e coordenadora de área. Universidade Estadual do Rio Grande do Sul/UERGS. E-mail: mirna-martinez@uergs.edu.br 


\title{
THE IDENTITY AND ACADEMIC LITERACIES MARKED THROUGH POETRY
}

\begin{abstract}
This work is the result of a qualitative research conducted with students of Projovem Urbano in the city Bagé / RS. Assuming that thinking of identity is also thinking about language, that is, thinking of identity construction as a process that is changing (HALL, 2011), this research was held in order to analyze, from the model of academic literacies (LEA \& STREET, 2006), the process of building the identity of the Projovem Urbano students. It was used as analytical tools, language marks found in poems produced by the students with reference to the poetry "Ou isto ou aquilo" by Cecilia Meirelles. The data indicate that there is, on the part of these young people, the desire not to lose their roots, but with a willingness to change and become autonomous. The data indicate also a subject with a postmodern design that assumes different identities at different times. It is also pondered the academic literacies were present, as were beyond the definition or use of specific rules. On the contrary, they represented the different ways in which these young people (GEE 1999) value, think, believe and write through the textual poetry genre.
\end{abstract}

Keywords: Identity. Literacy. Poetry.

\section{INTRODUÇÃO}

No mundo atual, torna-se necessário cada vez mais, o indivíduo estar preparado para enfrentar o mercado de trabalho. De tal maneira que se busca, através do ensino, uma preparação para o mesmo. Modifica-se, com isso, o pensamento que de certa forma trará mudanças na vida de qualquer sujeito. Dessa maneira, pode-se dizer que o "eu" passa por alterações que se estabelecem de um modo inconsciente. De acordo com Hall (2011, p.38), "a identidade é realmente algo formado, ao longo do tempo, através de processos inconscientes e não algo inato, existente na consciência no momento do nascimento". De modo que a identidade vai modificando o nosso "eu" através de influências exteriores que se recebe. Assim, muda-se e reestrutura-se a maneira de pensar, agir e expressar. $\mathrm{O}$ Projovem Urbano, Programa do Governo Federal, surgiu com esta finalidade e, com intuito social de incluir jovens que por um motivo ou outro não concluíram o Ensino Fundamental. Ademais, tem como princípio fundamental a já afirmada integração entre Formação Básica, Qualificação Profissional e Participação Cidadã (MEOG, 2012, p.34).

Para os alunos do Projovem, a identidade seja ela cultural, nacional ou linguística, foi sendo modificada ao longo dos meses. De acordo com Hall (2011), a identidade cultural está relacionada com a língua, religião, costume, tradição e sentimento de um povo. Por conseguinte, a cultura vai sendo compartilhada e transformada, tanto dentro da sala de aula como fora dela. Pela mesma razão, buscam-se mudanças de pensamento, comportamento, deixando de lado algumas vezes o machismo das famílias para enfrentar as diferenças da sociedade.

O programa tinha como proposta proporcionar a conclusão do ensino fundamental a alunos com idade entre 18 a 29 anos. Destaca-se que muitas jovens são mães solteiras que querem continuar estudando para poder acompanhar seu 
(sua) filho (a) nas tarefas escolares. A educação modifica-se para tal realidade e, portanto, as aulas do Programa são planejadas, estudadas e pensadas para dar conta desse público. Nas práticas das aulas são abordados temas atuais sempre com o apoio das formações que os educadores têm ao longo dos dezoito meses, tempo que dura o Programa. As propostas foram contempladas por diferentes gêneros textuais tendo como foco a leitura e a escrita compreendidas como práticas sociais (LEA \& STREET, 2006). Através das práticas os alunos foram construindo seu discurso o que foi observado no dia a dia da sala de aula e na convivência entre o grupo. Isso vem reforçar o reconhecimento do trabalho realizado pelos educadores do Programa.

O presente artigo é resultado de uma pesquisa e, ao mesmo tempo, uma inquietação que surgiu de uma das autoras que atuava como educadora de língua portuguesa no Projovem. Ao compreender o processo dos alunos no ensino/ aprendizagem da língua portuguesa como prática social, percebe-se que existem marcas que se configuram quando são propostas atividades de escrita. Para a realização desta pesquisa, partiu-se do seguinte objetivo: analisar, a partir do modelo dos letramentos acadêmicos, como se dá o processo de construção da identidade dos alunos do Projovem Urbano. Para fins de análise, foram utilizadas algumas marcas linguísticas encontrados em poesias produzidos pelos alunos, tendo como motivador para tal produção, a poesia "Ou isto ou aquilo" (2012), da autora Cecília Meileres.

\section{CONCEPÇÓES DE IDENTIDADE}

Nas últimas décadas, estudos têm demonstrado que estão ocorrendo mudanças no campo da identidade. Por isso, é importante pontuar, neste estudo, diferentes concepções de como a identidade se forma ou constrói e os processos que ocorrem e se entrecruzam.

No sentido filosófico, para Heidegger (2006, p.38-52), o princípio da identidade pode ser visto através da fórmula $A=A$. Essa fórmula poderia parecer que designa o princípio da igualdade entre os dois elementos da fórmula. Mas não é assim.

O autor busca no latim o que é idêntico, vêm de idem que se designa em grego como to autó, que traduzido para o português significa 'o mesmo'. Heidegger (2006, p.38), diz que "para que algo possa ser o mesmo, basta cada vez um. Não é preciso dois como na igualdade". Para Heidegger "A fórmula fala de uma igualdade. Ela não nomeia $\mathrm{A}$ como o mesmo. A fórmula corrente para o princípio da identidade encobre o que o princípio quereria dizer: A é A, cada A é ele mesmo o mesmo" (2006, p.38).

Heidegger (2006) analisa o princípio da identidade em Platão e Parménides. Em Platão aparece a identidade como "cada um ele mesmo para si mesmo o mesmo" (p. 41). Por isso, a identidade aparece através da história do pensamento ocidental, com o caráter da unidade e representada abstratamente. $\mathrm{O}$ autor pontua 
que não é somente mudar a fórmula de $\mathrm{A}=\mathrm{A}$ para $\mathrm{A}$ é $\mathrm{A}$ que o significado de identidade e qual o seu lugar, pode ficar resolvido.

$\mathrm{Na}$ análise de Heidegger, para Parmênides o apelo da identidade fala desde o ser do ente. $\mathrm{O}$ teor da identidade em Parmênides é "o mesmo, pois, tanto é apreender (pensar) como também ser" (p. 41). Portanto, coisas diferentes, pensar e ser, são pensadas como o mesmo. Para ele: "Pensar e ser têm seu lugar no mesmo e a partir deste mesmo formam uma unidade".

"Ser" representa o comum-pertencer no sentido da identidade. O ser é determinado a partir de uma identidade, como um traço desta identidade. Mais tarde, a identidade pensada na metafísica é representada como um traço do ser. Ao esclarecer o comum-pertencer, Heidegger apresenta os dois sentidos do mesmo:

Comum-pertencer mostra o possível sentido hegeliano da identidade entre ser e pensar, ser e homem: identidade resultado de um processo, de uma mediação conduzindo a uma síntese. Também aponta para um âmbito ( o mesmo) do qual fazem parte homem e ser; é a identidade heideggeriana que resulta do passo de volta. A diversa leitura da palavra procura mostrar os dois caminhos - ambos recusando a identidade como estático traço do ser; um em direção de um telos (fim), de uma síntese suprema, outro em direção da arché (começo), do fundamento (HEIDEGGER, 2006, p. 42).

No sentido comum, ao pensar comum-pertencer com ênfase na primeira parte da expressão, o sentido de pertencer é determinado a partir da comunidade, quer dizer, a partir de sua unidade. Nesse caso, "pertencer" significa integrado, inserido na ordem de uma comunidade, instalado na unidade de algo múltiplo, reunido para a unidade do sistema, mediado pelo centro unificador de uma adequada síntese: "A Filosofia representa este comum-pertencer como nexus e connexio, como a necessária junção de um com o outro" (p. 43). Entretanto, pode ser pensada diferentemente, com ênfase no pertencer. Isso quer dizer "que agora esta indicação nos faça notar a possibilidade de não mais representar o pertencer a partir da unidade da comunidade, mas de experimentar esta comunidade a partir do pertencer" (p. 44).

Ao conceituar e explicar a noção de Identidade pode-se concordar com Woodward (2004, p.10) que "a construção da identidade é tanto simbólica quanto social". Para a autora, a construção da identidade é relacional e a diferença é estabelecida por uma marcação simbólica relativamente a outras identidades. Também, a identidade caracteriza-se pela sua vinculação a condições sociais e materiais.

Nessa relação, o social e o simbólico referem-se a dois processos diferentes, mas cada um deles é necessário para a construção e a manutenção das identidades. Ainda, Woodward (2004) adiciona outro elemento que é a representação, assim expressa:

A representação inclui as práticas de significação e os sistemas simbólicos por meio dos quais os significados são produzidos, posicionando-nos como sujeito. É por meio dos significados produzidos pelas representações que damos sentido à nossa experiência e àquilo que somos. Podemos inclusive 
sugerir que esses sistemas simbólicos tornam possível aquilo que somos e aquilo no qual podemos nos tornar (WOODWARD, 2004, p. 17).

A autora acrescenta que as mudanças e transformações globais nas estruturas políticas e econômicas no mundo contemporâneo, "colocam em relevo as questões de identidade e as lutas pela afirmação e manutenção das identidades nacionais e étnicas" (ibid: p.24). Também não se pode excluir a competição e o conflito entre as diferentes identidades, pois os sujeitos falam a partir de uma posição histórica e cultural específica.

Ao perceber as semelhanças e diferenças na construção da identidade, Hall (2011) considera que a mesma está descentrada, ou seja, deslocada ou fragmentada. Sob esse viés, a identidade não é única e está aberta a formulações e contestações. Pode-se dizer, então, que há um duplo deslocamento, uma vez que as transformações e as mudanças estruturais na paisagem cultural de classe, gênero, etnia, raça e nacionalidade mudam, consequentemente, a identidade pessoal.

Esse duplo deslocamento - descentração dos indivíduos tanto de seu lugar no mundo social e cultural quanto de si mesmos- constitui uma "crise de identidade" para o indivíduo. Esses processos de mudança, tomados em conjunto, representam um processo de transformação tão fundamental e abrangente que transformam a própria modernidade.

Hall (2012) indica três concepções de identidade: a) O sujeito do Iluminismo baseava-se numa concepção de pessoa humana como um indivíduo totalmente centrado, unificado, dotado das capacidades de razão, de consciência e de ação, cujo centro consistia num núcleo interior, que emergia quando o sujeito nascia e com ele se desenvolvia, ainda que permanecendo essencialmente o mesmo, ao longo da existência do indivíduo. Era uma concepção "individualista" do sujeito e de sua identidade;

b) O sujeito sociológico refletia a complexidade do mundo moderno e a consciência de que esse núcleo interior do sujeito não era autônomo e autossuficiente, mas era formado na relação com os outros, que mediavam para o sujeito os valores, sentidos e símbolos - a cultura dos mundos que ele habitava. A identidade é formada na interação entre o eu e a sociedade. O sujeito tem uma essência interior que é o "eu real", mas este é formado e modificado num diálogo contínuo com os mundos culturais "exteriores" e as identidades que esses mundos oferecem. Essa concepção que estabiliza os sujeitos está mudando. As mudanças estruturais e institucionais tornam o sujeito fragmentado. O próprio processo de identificação tornou-se provisório, variável e problemático. Esse processo produz a terceira concepção que é (c) o sujeito pós-moderno, aquele que não tem uma única identidade fixa, essencial ou permanente. A identidade é formada e transformada continuamente em relação às formas pelas quais somos representados nos sistemas culturais. Ela é definida histórica e socialmente e não biologicamente. O sujeito assume identidades diferentes em diferentes momentos, identidades que não são unificadas ao redor de um "eu" coerente. As identidades são, portanto, múltiplas e mutantes e só existe a possibilidade de nos identificarmos temporariamente. 
Da mesma forma, o processo de viabilizar a construção da identidade cultural dos jovens, infere-se na mudança, que advém de um lado na integração dentro do programa, da interação aluno/aluno; aluno/professor e também das disciplinas do currículo do Projovem.

Nesse sentido, compreende-se que é oportuno trazer para esta reflexão o entendimento de Orlandi (2002) quando se refere à identidade linguística escolar e, cita algumas dessas reflexões "a identidade é um movimento na história; ao significar o sujeito se significa; identidade não se aprende" (ORLANDI, 2002, p.204). De acordo com a autora um movimento na história, quer dizer que a identidade não é sempre igual, não é homogênea. Fala-se a mesma língua, mas de maneiras diferentes cada sujeito com sua singularidade. Por sua vez, quando se refere a "movimento" a identidade se desloca em varias posições que cada sujeito tem em particular, ou seja, como a de professor, mãe, pai. Embora se assumam determinadas funções dentro da sociedade, isso vai permitir que cada sujeito possa formar sua própria história.

Também outra reflexão que Orlandi (2002) apresenta é "ao significar, o sujeito se significa" que, neste caso, está relacionada ao mecanismo de produção de sentidos do sujeito. Quando o professor, por exemplo, corrige o aluno, ele por sua vez intervém nos sentidos que este aluno está produzindo e, assim, interfere na constituição de sua identidade. Por último, "identidade não se aprende", ou seja, ela faz parte do jogo entre a língua e a história, que por sua vez, está relacionada aos sentidos que cada sujeito possui, de modo que cada um se identifica com certas ideias ou assuntos que acabam dando sentido e/ou significado com o que acredita.

Bauman (2005) apresenta o conceito de identidade como sendo uma entidade abstrata, virtual e sem existência concreta. A identidade possui por definição uma dimensão conflitante, porém é essencial como ponto de referência para os grupos sociais, já que os une na diversidade e permanece na mudança. Também significa um processo de (re) classificação dos grupos em categorias socialmente construídas a partir de certos elementos culturais, tomado como referência pelo grupo em relação a outro(s) grupo(s) tais como: a língua, religião, rito, raça, nação, símbolos, etc. Dessa maneira, o conceito de identidade, entendido como reconhecimento de pessoas ou grupos sociais, pressupõe inconscientemente a ideia da diferença.

Os registros linguísticos apontados neste trabalho ficaram por conta da produção textual aqui mencionada, gênero poesia. E, a continuação para compreender melhor, foram apresentadas nas análises, as marcas linguísticas o que permitiu verificar essas ocorrências.

\section{LETRAMENTOS ACADÊMICOS: OBJETO DE REFLEXÃO}

Existe uma preocupação por parte não só de educadores, mas da sociedade em geral com relação ao desenvolvimento de habilidades para utilizar a leitura e a escrita. No entanto, é preciso questionar que desenvolver somente essas habilidades não seria suficiente para os usos efetivos da leitura e escrita como práticas sociais. Dessa maneira, os estudos teóricos relacionados à leitura, à escrita, compreendidas 
como práticas sociais, tanto em nível universitário como nos níveis fundamentais e médios (e aqui, inclui-se alunos dos Projovem), vêm sendo guiados por discussões do grupo dos Novos Estudos do Letramento (LEA \& STREET, 2006). Precisase ponderar que definir letramento acadêmico torna-se difícil porque vai além de definir regras específicas, vai além da decodificação ou codificação da linguagem. Pelo contrário, implica formas de estar no mundo. Representa um conjunto de convenções que determinam os modos (GEE, 1999) de se comportar, interagir, valorizar, pensar, acreditar, falar, ler e escrever. Envolve, então, os conhecimentos processual e do contexto, bem como conhecimento de conteúdo.

Essas discussões estão fundamentadas, através de três modelos (LEA \& STREET, 2006) ou perspectivas sobrepostas: competências, socialização acadêmica e do letramento acadêmico, os quais serão explicitados na sequência.

Com relação ao modelo de competências a leitura, a escrita e o letramento são vistos como habilidades individuais e cognitivas. Nessa perspectiva, o estudante somente transfere, de um contexto para outro, aquilo que já conhece e as propostas pedagógicas são focadas somente nas características formais da linguagem, preocupando-se somente com a transmissão do conhecimento. De acordo com Lea \& Street (2006), o modelo da socialização acadêmica compreende que uma vez aprendidas e compreendidas as regras, os alunos são capazes de reproduzi-las sem problemas em outro contexto, adaptando-as de forma automática dentro de cada especificidade. Os autores discutem, então, um terceiro modelo: o dos letramentos acadêmicos. Esse modelo vai além de competências e socialização, uma vez que vê os processos de aprendizagem mais complexos, pois:

relaciona a aquisição do letramento e seus usos efetivos de forma mais
adequada, dinâmica, considerando suas particularidades. Letramentos
acadêmicos incluem, também, as relações de poder entre as pessoas,
instituições e identidades sociais. Foca não só a relação existente entre
epistemologia e os processos sociais, mas também, de modo mais geral,
em exigências institucionais, bem como em contextos mais específicos, nas
diferenças individuais dos professores ou, ainda, na individualidade dos
alunos (SILVA, p.28 2015).

Salienta-se, no entanto, que o modelo dos letramentos acadêmicos complementa-se nos dois modelos anteriores. No entanto, esse modelo amplia seu foco e dá especial atenção às relações de poder, autoridade, construção de sentido e identidade que estão implícitas no uso de práticas de letramento. Reforça-se que os três modelos ou perspectivas (LEA E STREET, 2006), estão relacionadas às conceitualizações particulares de linguagem e, também, às teorias de aprendizagem, cada uma com suas próprias raízes e tradições associadas.

\section{A ESCRITA ATRAVÉS DE GÊNEROS TEXTUAIS}

Para que o aluno seja academicamente letrado é preciso que ele mobilize estratégias (FISCHER, 2008) que façam parte do seu repertório e possa, posteriormente, compreender e usar as linguagens específicas do domínio 
acadêmico. No entanto, não basta somente oferecer textos específicos de domínio acadêmico sem, antes, compreender os diferentes gêneros que circulam no diaa-dia. Desse modo, cada gênero textual, na sua especificidade, contribui para organizar as atividades comunicativas que na visão de Marcuschi (2005),

[...] são fenômenos históricos, profundamente vinculados à vida cultural e
social [...] contribuem para ordenar e estabilizar as atividades comunicativas
do dia-a-dia. [...] Caracterizam-se como eventos textuais altamente maleáveis,
dinâmicos e plásticos. Surgem emparelhados a necessidades e atividades
socioculturais, o que é facilmente perceptível ao se considerar a quantidade
de gêneros textuais hoje existentes em relação a sociedades anteriores à
comunicação escrita (MARCUSCHI, 2005, p.19).

Nessa perspectiva, os gêneros textuais se configuram na sua função social e tem como papel de realizar uma (ou mais de uma) razão determinada em uma situação comunicativa (um contexto) para promover uma interação específica. O trabalho realizado na sala de aula com os gêneros textuais foi pertinente para atingir objetivo dessa pesquisa. Também esclarecedor para esses alunos que não sabiam diferenciar um gênero de outro. Pensando nisso, cita-se outra definição de Marcuschi:

[...] usamos a expressão gênero textual como uma noção propositalmente vaga para referir os textos materializados que encontramos em nossa vida diária e que apresentam características sócio-comunicativas definidas por conteúdos, propriedades funcionais, estilos e composição característica. Se os tipos textuais são apenas meia dúzia, os gêneros são inúmeros. Alguns exemplos de gêneros textuais seriam: telefonema, sermão, carta comercial, carta pessoal, romance, bilhete, reportagem, jornalística, aula expositiva, reunião de condomínio, notícia jornalística, horóscopo, receita culinária, bula de remédio, lista de compras, [...] (MARCUSCHI, 2005, p. 22-23).

Os gêneros textuais permitem relacionar vários conhecimentos e eles estão ancorados em diversos modelos pré-definidos e assim se apresentam para o leitor e interlocutor. Também são tipos estáveis de enunciado, com estruturas e conteúdos temáticos que facilitam sua definição.

Para esta pesquisa foi utilizado o gênero poesia que é um gênero literário caracterizado pela composição em versos estruturados de forma harmoniosa. Considera-se uma manifestação de beleza e estética retratada pelo poeta em forma de palavras. Também, pode-se dizer que no sentido figurado, a poesia é tudo aquilo que comove e que sensibiliza, de modo que desperta sentimentos. No entanto, é qualquer forma de arte que inspira e encanta. Para escrever um texto poético existem determinados elementos formais que o caracteriza como, por exemplo, o ritmo, os versos e as estrofes que definem a métrica de uma poesia.

O estimulo à leitura não se resume apenas em fazer com que os alunos leiam, mas que esse seja um ato e exercício crítico. Para isso, durante as aulas de língua portuguesa do Projovem realizaram-se leituras de diversos gêneros, com intuito de apresentar a literatura aos alunos. Neste caso foi escolhida a poesia porque está para além da linguagem poética, está para linguagem da vida. 
Assim, como na sua carga máxima de significado e de reflexão, poesia como pensante, mas também sentimento, emoção, com função social, com caráter humanizado, ético e, capaz de mudar o mundo. Deste modo, resultou um trabalho compensatório, exteriorizando os sentimentos dos alunos.

Cecília Meireles, autora escolhida para o presente trabalho, expressa o mundo da criança e/ou adulto, o cotidiano e interesses dos leitores em suas poesias, inovando temas populares com musicalidade, versos livres, aliterações, rimas, etc., permitindo assim, diferentes níveis de leitura. Na poesia "Ou isto ou aquilo" (1990), a autora expressa às insatisfações com os limites e desejos.

Trabalhar com a leitura na sala de aula é uma das exigências do programa, isso se faz diariamente, porém, o que mais chamou atenção da educadora foi que os alunos gostavam de ler algo que tocasse seus sentimentos. Então, selecionavam-se textos narrativos em que o aluno pudesse refletir sobre seu cotidiano. Observouse que a poesia foi um dos gêneros de fácil compreensão por parte dos alunos, provavelmente pela sua estética o que justifica sua escolha para o presente estudo.

Regina Ziberman (2005) defende o trabalho com leitura, bem como a importância de formar leitores. Por essa razão, destaca-se a seguinte reflexão da autora:

Introduzindo- se nos versos e nas estrofes, a perspectiva de jogo e de brincadeira, o gênero poético pôde se livrar dos problemas que experimentaram principalmente a metade do século XX. O elenco de autores diversificouse, e várias possibilidades expressivas apareceram... e passaram a construir as características mais importantes da poesia direcionada prioritariamente ao público formado por meninos e meninas brasileiras" (ZIBERMAN, 2005, p. 130).

Assim, compreende-se que o trabalho com o gênero textual poesia poderá permitir, através da criação e jogos de palavras, reflexões sobre os modos de ser e, ainda, entusiasmar os alunos do Projovem com relação à leitura e à produção de texto.

\section{CAMINHOS METODOLÓGICOS}

Para o presente trabalho realizou-se um estudo de caso com uma abordagem qualitativa, interpretativa, de caráter observacional. Segundo Bortoni-Ricardo (2008), a interpretação dos fenômenos e a atribuição de significados são básicos no processo de pesquisa qualitativa. Os sujeitos foram alunos matriculados no Projovem Urbano da cidade de Bagé/ RS.

O critério para escolha dos sujeitos para referida análise deu-se, uma vez que os mesmos manifestavam-se nas aulas, de língua portuguesa, que não mudariam quanto "a seu jeito de ser". Sempre que se debatia em aula a necessidade de melhorar alguns aspectos da língua, conforme sua necessidade, esses sujeitos acreditavam que isso não faria a diferença na sua vida pessoal. Importante esclarecer, ainda, que 
não houve preocupação quanto à rima, métrica, versos, tudo que estrutura esse gênero. A escrita das poesias foi realizada no mês de agosto de 2014.

Esta investigação define-se como um Estudo de Caso, pois está dirigida a um grupo específico, como esclarecem Lüdke e André: “o estudo de caso é o estudo de um caso, seja ele simples e específico ou complexo e abstrato" (2011, p.17). Eis que o mesmo permite estudar algo singular, mas com valor em si mesmo.

Como instrumento desta pesquisa utilizou-se a poesia "Ou isto Ou aquilo" da autora modernista Cecília Meirelles. A partir disso a educadora lançou a proposta para cada aluno elaborar uma poesia registrando nele suas marcas pessoais. Assim que os alunos compreenderam as funções das conjunções dentro de um contexto, começaram a efetuar seus registros. O trabalho teve, num primeiro momento, uma escrita e, após, algumas correções, a reescrita. Com isso, cada aluno expôs através do gênero poesia seus sentimentos, o que foi permitido deixar marcas/ pistas identitárias. As discussões contemporâneas trazem em particular a visão de identidade do sujeito atual como sendo constituída de várias e não apenas de uma identidade, e que tais identidades são muito mais efêmeras que estável o que gerou um embate entre a identidade construída socialmente e a subjetividade de cada um.

Os sujeitos analisados nesta pesquisa são alunos do Projovem Urbano núcleo Bagé/ RS. Embora tenham participado trinta alunos de ambos os sexos com idade de 18 a 29 anos, para efeito da análise, foram selecionados três sujeitos cujos nomes foram alterados para preservar a sua identidade.

Explicita-se a escolha dos três para referida análise, uma vez que se observou marcas pertinentes na sua produção, tais como os verbos acreditar, esquecer, encontrar, escolher, ficar, etc. Através do jogo de palavras e misturando sentimentos foram produzidas as poesias. A proposta apresentada em sala de aula era que cada aluno escrevesse uma poesia escolhendo uma ou mais conjunções alternativas.

\section{O QUE DIZ A PRÁTICA E O QUE REVELA O GÊNERO TEXTUAL}

O presente tópico apresenta uma análise de três poesias de sujeitos diferentes, alunos do Projovem Urbano. Os recortes apresentados foram extraídos do corpus da pesquisa que reúne os dados coletados. As análises apresentadas estão embasadas nos teóricos que deram suporte a este artigo.

Sujeito1 - Mirian

\section{Talvez - Talvez}

Talvez eu acredite em alguma coisa ou

Talvez alguma coisa faça en acreditar

Talvez en esqueça o meu passado

Talvez o meu futuro possa mudar

Talvez o meu amanhã irá chegar;

Ora, ora! E se ele não chegar 
Ora! Vou ter que me mudar

Talvez, eu não mude

Talvez tenha que me preparar

Quero acreditar nas minhas decisões,

Quero acreditar que eu possa mudar;

Talvez tenha que esquecer meus medos

Talvez eu tenha que lutar para men futuro eu enfrentar;

Talvez. eu tenha que me animar e acreditar que o eu amanhá;

Já, já irá chegar!

A fim de conhecer e analisar o que cada aluno (sujeito) apresenta em relação à escrita das poesias, seleciona-se o primeiro sujeito denominado Mirian que inicia sua poesia com a conjunção "talvez" estabelecendo uma relação de possibilidades quando diz: "talvez acredite em alguma coisa; ou talvez alguma coisa faça eu acreditar". Nesta primeira frase esse sujeito já começa dando uma ideia de incerteza, imprecisão e, em seguida usa o verbo "acreditar" aqui o empregou com sentido de esperança e de fé, finaliza sua frase dizendo "em alguma coisa".

Observa-se que Mirian inicia sua produção com frases que dão ideia que está em busca de esperanças. No entanto, essa busca integra-se na sua identidade como um progresso à "luź e ao sol”, o que dá indícios de coerência, consciência e conhecimento de quem ela é. É possível, ainda, constatar uma articulação do inconsciente proclamado através da linguagem literária e como bem menciona "em alguma coisa", com a perspectiva de que poderá existir algo melhor.

$\mathrm{Na}$ segunda estrofe, Mirian continua sua afirmação ao utilizar a mesma conjunção, "talvez esqueça meu passado; talvez meu futuro possa mudar; talvez, o meu amanhã irá chegar". De fato, essas buscas por algo melhor, estão presentes no início de sua poesia. Esquecer o passado acreditar no futuro demonstra sua vontade em ter novas perspectivas. $\mathrm{O}$ que reforça o pensamento de que a identidade se modifica. De modo que esse sujeito mostrou, através do jogo de palavras, que realmente está buscando uma transformação de vida de esperança.

Seguindo a mesma análise, verifica-se que, na terceira estrofe, Miriam, coloca dúvidas quanto a seu futuro "Ora, ora! E se ele não chegar; Ora! Vou ter que me mudar". Nesta estância apesar de estabelecer dúvidas com relação a seu futuro é preciso de "um objetivo" (BAUMAN, 2005), algo a ser definido. Na continuação diz "Quero acreditar nas minhas decisões, Quero acreditar que eu possa mudar;", aqui demarca uma esperança quer acreditar num amanhã, numa nova etapa de vida em mudanças, tudo que possa vir acontecer.

Por último, conclui sua poesia e coloca muitas expectativas em relação ao seu futuro, "Talvez tenha que esquecer meus medos; Talvez eu tenha que lutar para men futuro eu enfrentar”. A utilização dessas palavras perfaz-se o que esse sujeito vem indicando na sua poesia, sempre com esse anseio. No final "Talvez, eu tenha que me animar e acreditar 
que o eu amanhã; Já, já irá chegar!' comprova-se que existe um grande desejo em querer "lutar para enfrentar seu futuro". Para Hall (2011) as identidades representam um processo de "transformação", essa na qual se deseja e se busca. Enfim, é possível inferir que há indícios por parte desse sujeito em querer enfrentar o futuro o que virá acontecer sem medo, sem desânimo e com confiança.

\section{Sujeito2 - Cintia}

\section{Talvez Sim, Talvez Não}

Talvez as nossas vidas não tenham um propósito;

Talvez tudo que acreditamos esteja errado;

Por ora, encontramos pessoas boas na nossa vida;

Por ora não,

Ou escolho umas;

On escolho outras.

Mas uma coisa tenho certeza;

Sempre vou escolher você!

Prosseguindo as análises, o sujeito 2 denominado Cíntia, começa com um título assim: "Talvez sim, talvez não". No começo estabelece dúvidas uma vez que utiliza uma afirmação e uma negação ao mesmo tempo. Isto é, demonstra oposições quanto ao que deseja, "a complexidade da vida moderna exige que assumamos diferentes identidades, mas essas diferentes identidades podem estar em conflito" (WOODWARD, 2004, p.31). Em seguida introduz na sua poesia, o seguinte: "Talvez as nossas vidas não tenham um propósito; Talvez tudo que acreditamos esteja errado"; percebem-se certas marcas linguísticas em que dúvida e incerteza estão juntas no seu discurso. Contudo introduz um advérbio e por ser uma palavra invariável da língua e tem a função de modificar um verbo, neste caso, os verbos "ter" e "acreditar", com intuito de expressar o que Orlandi (2002) menciona em identidade e língua; é comum associar língua com identidade, logo, a mesma se relaciona com a cultura, nacionalidade. Portanto, esse sujeito expressa essa relação nas estrofes demonstrando caminhos a serem seguidos.

$\mathrm{Na}$ segunda estrofe, estabelece uma relação de comparação quando coloca "Por ora, encontramos pessoas boas na nossa vida; Por ora não", quando usa a conjunção disjuntiva encontrar pessoas boas significa encontrar alguém que se importe e que, talvez, faça a diferença na sua vida. Porém, faz referência, também as que não são. Para Hall (2011, p.21) "a identidade muda de acordo como o sujeito que é interpelado, a identificação não é automática, mas pode ser ganhada ou perdida". Existem diferenças sociológicas quando se procura ser de uma maneira ou de outra, talvez isso provoque dúvidas quanto ao que se deseja "ser e querer".

Na sequência, já na terceira estrofe menciona "Ou escolho umas; Ou escolho outras" nesta outra frase estabelece uma escolha incerta sem muita identificação. Seguindo o pensamento de Hall (2011) as palavras são "multimoduladas", pensando no 
sentido de significado o que coloca em dúvida na sua escolha. Esse viés provoca o que teóricos como Hall menciona os significados das palavras surgem nas relações similares e diferentes.

Por último, fechando a poesia "Mas uma coisa tenho certeza; Sempre vou escolher voce?" nesta última frase, coloca uma certeza no que diz e, por sua vez, demonstra uma contradição no discurso anterior. O que se percebe na decisão quando menciona "você". Para Orlandi (2002) os sentidos não são algo que se dá independente do sujeito. Os dois se concebem em única coisa e ao mesmo tempo. Nesse sentido, as relações afetivas marcam esse sujeito, finalizando sua poesia com traços da sua identidade. Destaca-se, revelado pelo sujeito, que "você", no final da sua escrita, foi direcionado para sua professora uma vez que lhe deu a oportunidade de externalizar seus sentimentos.

Sujeito 3- Gabriela

\section{Lembranças}

Ora, ora cadê aqueles momentos que ficaram na memória;

Ora, ora cadê aqueles que ficarão pra bistória;

Talvez tenha amigos, talvez já tive os melhores;

Sejam eles bons, sejam eles ruins;

Os bons já, já guardei na memória;

Os ruins já, já deixei pra historia;

Eu quer queira, quer não sofri por perder meu irmão;

Talvez as pessoas passam em nossa vida por acaso;

Talvez não seja por acaso que elas permaneceram;

Seja eu, seja você dos amigos não podemos desfazer;

Já, já dos verdadeiros amigos vou lembrar!

Quer queira, quer não meu amigo Leandro não sai do meu coração.

Gabriela começa sua poesia com as conjunções disjuntivas relacionando passado e futuro, uma vez que utiliza o mesmo verbo (ficar), porém, em tempos diferentes. Embora estabeleça uma relação de saudosismo, quando menciona "cadê aqueles momentos", esse sentimento é coerente/esperado, pois faz referência à identidade como sendo um movimento na história "uma mexida na relação entre formações discursivas, no conjunto da memória" (ORLANDI, 2002, p.207). Esse sujeito quando introduz na sua poesia questionamentos que marcaram sua vida, apresenta indícios de que buscou na memória algo que provocou saudades, sejam elas boas ou ruins.

$\mathrm{Na}$ próxima estrofe, coloca os sentimentos com relação às amizades que teve "Talvez, tenha amigos, talvez já tive os melhores; Seja eles bons, seja eles ruins; Os bons já... já guardei na memória; Os ruins já... já deixei pra história;". Percebe-se que a identidade está 
marcada por esses momentos mencionados anteriormente que foram acentuadas na vida desse sujeito, dando sentidos a esses modos de ser (GEE, 1999) e agir.

Gabriela, ao retomar os momentos que ficaram na memória, vai se constituindo como sujeito com sua singularidade (ORLANDI, 2002) e mostra que sua identidade não é homogênea. Há um movimento que se desloca ao fazer suas escolhas, uma vez que, para ela, é possível guardar na memória ao expressar "ficaram na memória" ou, deixar pra traz ao dizer "ficarão pra história". Assim, pela mesma razão, logo, continua: "Eu quer queira, quer não sofri por perder meu irmão; Talvez, as pessoas passam em nossa vida por acaso; Talvez. não seja por acaso que elas permaneceram". Novamente Gabriela, no início da poesia, faz uma reflexão sobre o que ocorreu no seu passado, utilizando o letramento como estratégia (FISCHER, 2008) numa prática situada.

Por fim, nota-se quanto é importante a questão da amizade para Gabriela quando menciona explicitamente o nome do amigo que não quer esquecer conforme revela: "Seja eu, seja você dos amigos não podemos desfazer; Já... já dos verdadeiros amigos vou lembrar! Quer queira, quer não meu amigo Leandro não sai do meu coração." Nesta última estrofe, expressa saudades ao amigo que partiu e o coloca como um dos amigos verdadeiros que passaram na sua vida.

Pela mesma razão, quando utiliza a conjunção disjuntiva “quer" junto ao verbo "queira" expressando um desejo, uma ansiedade e, assim, finaliza sua poesia fazendo uso das conjunções alternativas, bem como, revelando emoções ao leitor. Portanto, através da poesia, esse sujeito conseguiu expressar sentimentos que talvez tivessem guardados em sua memória. Esses sentimentos são contraditórios (HALL, 2011) uma vez que existe um conflito entre a parte "boa" e "má", consequentemente, a identidade é formada e transformada ao longo do tempo, está sempre incompleta, em desenvolvimento. Ela vai formando-se através do pensamento com ajuda da interação tanto na sala de aula como em casa com a família, amigos, etc.

Pode-se deduzir que os dizeres dos 3 sujeitos representam um conjunto de convenções que provavelemente determinam os modos (GEE,1999) de cada um de se comportar, interagir, valorizar, pensar, acreditar, falar, ler e escrever. Também é possivel destacar o quanto os letramentos acadêmicos estiveram presentes, uma vez que cada um, considerando suas particularidades (SILVA, 2015), conseguiu relacionar a aquisição do letramento com seus usos efetivos de forma adequada e dinâmica.

\section{CONSIDERAÇÓES FINAIS}

De modo geral, esta investigação buscou traçar algumas reflexões sobre o objetivo estabelecido no início desta pesquisa, como também, tentar responder às inquietações motivadoras que inspiraram este trabalho. Considerando que os jovens de hoje procuram interagir em vários espaços sociais o que, de certa forma, contribui para formação e transformação da sua identidade. A partir das reflexões postas, é possível dizer que o processo de ensino / aprendizagem impacta 
as identidades desses sujeitos, como também as representações discursivas que influenciam na construção identitária dos mesmos.

Embora o texto poético tenha sido um desafio para esses jovens, foi possível verificar que através da escrita deixaram marcas linguísticas que representam o uso dessa escrita como prática social, bem como os sentimentos que os envolvem. Apesar das incertezas, dúvidas na produção e, talvez algumas resistências causadas pelo tempo fora da escola, esses alunos lograram expressar emoções que se relacionam com o amor, amizade e sonhos que cada um tem, uma vez que os sujeitos são únicos, singulares e cada um possui histórias, sentimentos e recordações diferentes.

Enfim, o processo ensino/aprendizagem da língua nunca será um ambiente de completa harmonia, pois o encontro e a diversidade estabelecida na sala de aula trazem à tona questões que envolvem a identidade de um sujeito. Talvez, por isso, a experiência de falar de si, a partir da produção de poesias, pode ter sido para esses jovens uma das experiências mais mobilizadoras de identidade, pois, ao mesmo tempo em que a proposta os levou em direção ao novo, também os fez (re) encontrarem-se e perceberem o quanto são/podem ser sujeitos desse processo.

Por fim, os dados apontam que existe, por parte desses jovens, o desejo de não perder suas raízes, mas com uma vontade de mudar e se tornarem autônomos. Os dados podem indicar um sujeito com uma concepção pós-moderna em que assume identidades diferentes em diferentes momentos. Pondera-se, ainda, que os letramentos acadêmicos estiveram presentes, uma vez que foram além da definição ou uso de regras específicas. Pelo contrário, representaram os diferentes modos pelos quais esses jovens valorizam, pensam, acreditam e escrevem através da poesia. Envolveram, dessa forma, os conhecimentos processual e do contexto, bem como conhecimento de conteúdo, uma vez que conseguiram mostrar o quanto conhecem e sabem usar a sua língua.

\section{REFERÊNCIAS}

BAUMAN, Z. Identidade: entrevista a Benedetto Vecchi. Rio de Janeiro: Jorge Zahar Ed., 2005.

BORTONI-RICARDO, S. M. O professor pesquisador: introdução à pesquisa qualitativa. São Paulo: Parábola Editorial, 2008.

FISCHER, A. Letramento acadêmico: uma perspectiva portuguesa. Revista Acta Scientiarum. Language and Culture. Maringá. Jul./dez., v. 30, n.2, p. 177-187, 2008.

HALL, S.. A identidade cultural na pós-modernidade/ Tradução Tomaz Tadeu da Silva, Guaracira Lopes Louro- 11. Ed., 1.reimp. - Rio de Janeiro: DP\&A,2011.

HEIDEGGER, M. Que é isto, a filosofia?: Identidade e Diferença. Petrópolis: Vozes, São Paulo: Livraria Duas Cidades, 2006. Tradução de Ernildo Stein. 
LEA, M.R.; STREET, B.V.The academic literacies model: theory and applications.

Theory into Paractice. V.4, n.45, p.368-377, 2006.

LÜDKE, M. ANDRÉ, M. Pesquisa em educação: abordagens qualitativas. Menga - São Paulo: EPU, 1986. 13ª reimpressão, 2011

MARCUSCHI, L. A. In DIONÍSIO, A. P.; MACHADO, A. R.; BEZERRA, M. A. Orgs.

Gêneros textuais e ensino. 3 ed. Rio de Janeiro: Lucerna , 2005

MEIRELES, Cecília. Ou isto ou aquilo. In: Poesia Completa, Nova Fronteira, 1990- Rio de Janeiro, Brasil.

ORLANDI, E. P. Identidade Linguística Escolar. In: SIGNORINI, I. (Org.).

Lingua(gem) e Identidade: elementos para uma discussão no campo aplicado. Campinas, SP: Mercado de Letras, 2002.

SILVA, V.C. Relações entre letramento acadêmico no estágio supervisionado e práticas de ação docente na voz do aluno-professor. 2015.160f. Tese doutorado em Linguística Aplicada. Universidade Católica de Pelotas. Pelotas: UCPEL, 2015

WOODWARD, K. Identidade e diferença: uma introdução teórica e conceitual. In: SILVA, Tomaz, T. Identidade e diferença: a perspectiva dos Estudos Culturais. 5 ed. São Paulo: Vozes,2004.

ZIBERMAN, R. E para a poesia, não vai nada? In: Como porque ler a literatura infantil brasileira. Rio de Janeiro: Objetiva, 2005. Cap.12, p. 127 -143. 